\title{
Protection of Flax/PLLA Biocomposites from Seawater Ageing by External Layers of PLLA
}

\author{
A. Le Duigou, ${ }^{1}$ J. M. Deux, ${ }^{1}$ P. Davies, ${ }^{2}$ and C. Baley ${ }^{1}$ \\ ${ }^{1}$ LIMATB Laboratoire d'Ingénierie des Matériaux de Bretagne, Equipe Polymères et Composites, rue de Saint Maudé BP 92116 , \\ 56321 Lorient Cedex, France \\ ${ }^{2}$ IFREMER Centre de Brest, Materials and Structures Group, BP70, 29280 Plouzané, France
}

Correspondence should be addressed to A. Le Duigou, antoine.le-duigou@univ-ubs.fr

Received 14 March 2011; Revised 7 June 2011; Accepted 16 June 2011

Academic Editor: Vincent Verney

Copyright (C) 2011 A. Le Duigou et al. This is an open access article distributed under the Creative Commons Attribution License, which permits unrestricted use, distribution, and reproduction in any medium, provided the original work is properly cited.

\begin{abstract}
Biocomposites are sensitive to water, and previous work on flax reinforced PLLA showed a large drop in mechanical properties after immersion (Le Duigou et al. 2009). Unreinforced PLLA was much less sensitive. This paper presents a strategy to reduce the influence of wet ageing by adding extra layers of PLLA on the biocomposite surface. Weight gain measurements show that a PLLA coating $350 \mu \mathrm{m}$ thick reduces weight gain by half, and biocomposite stiffness and strength after ageing are improved by $100 \%$ compared to uncoated composite behaviour. Thermal analysis and microscopic examination are used to show damage mechanisms with and without protection. Property changes are shown to be quasilinearly related to weight gain.
\end{abstract}

\section{Introduction}

The pleasure boat industry generates large amounts of waste due to widespread use of glass fibre reinforced polyester composites. These materials pose end-of-life treatment difficulties, as glass fibres are very difficult to break down. They are also produced from nonrenewable resources. The development of biocomposites (associating natural fibres and biopolymers) is one alternative. For example, the flax/PLLA biocomposites show similar mechanical behaviour $[1,2]$, combined with low environmental impact compared to glass/polyester composites due to the use of flax fibres $[3,4]$. They are also recyclable after use, being based on a thermoplastic matrix [5], and can be composted at the end of their useful life [6].

However, there are some negative aspects. Natural fibres used as reinforcements are sensitive to high temperatures [7] and to water $[8,9]$. Their properties are also rather variable (according to growth conditions and variety) [10, 11]. When they are exposed to severe environmental conditions (immersion in sea water, e.g), several studies [12-14] have shown that biocomposites undergo degradation related to high water uptake, including hydrolysis, swelling, matrix cracking, and fibre/matrix debonding.
The conservation of biocomposite properties in such environments is thus a major issue if they are to be used in external applications. Different strategies can be developed to reduce water uptake in these materials. For example, chemical treatments [15-17] or physical treatments [16] of fibres are possible.

Another approach, used by $\mathrm{Hu}$ et al. [13] to protect jute/Poly (L-Lactic) Acid, is to apply an external film, $100 \mu \mathrm{m}$ of polypropylene in their case. Tests were performed at $70^{\circ} \mathrm{C}$ at $100 \%$ humidity and the film resulted in lower weight gain $(11.5 \%$ compared to $15.7 \%$ without the film) while conserving higher mechanical properties.

This is a similar approach to the use of external gelcoats on traditional composites. However, if we are to use such coatings on biocomposites they must also respect the environment. Gel coats are generally filled, coloured isophthalic polyester or vinyl ester resins; such materials are not compatible with the biosourced components of biocomposites as they come from nonrenewable resources and make end-of-life management by recycling or composting difficult. In a previous study [12], it was shown that PLLA absorbs little water during immersion (around $1 \%$ by weight after 3 months in seawater at $40^{\circ} \mathrm{C}$ ). Also, as shown by Tsuji and 
Suzuyoshi [18], its mechanical properties change little after immersion.

In order to benefit from these results, a method to place excess layers of PLLA film on the outer surfaces of flax/PLLA composites has been developed in order to provide a protective layer similar to a gel coat. The moulding of the biocomposite and coating is carried out in one operation. After use, the component is still recyclable and can be composted. The aim of the present study is to evaluate whether such coatings can effectively protect biocomposites by varying the coating thickness and analyzing the effects on mechanical and thermal properties after ageing in seawater.

\section{Material and Methods}

2.1. Materials. The reinforcements studied here are flax fibre mats. The flax fibres were grown in France and plants were subjected to dew retting before mechanical stripping and hackling. Flax mats were manufactured using a semiindustrial paper-making route [19] (pilot scale). Fibre length was $10 \pm 1 \mathrm{~mm}$, which results in a high aspect ratio $(L / d \approx$ 470) due to separation of fibre bundles during the process. The surface weight of the flax mats was around $230 \mathrm{~g} / \mathrm{m}^{2}$ and no physical or chemical pretreatments were used.

The biopolymer matrix was Poly-L-(lactic) acid PLLA of molecular weight $\left(M_{n}\right) 63000 \mathrm{~g} / \mathrm{mol}$ produced by Natureworks.

2.2. Manufacturing. Biocomposite plates $\left(280 \times 200 \mathrm{~mm}^{2}\right)$ were manufactured at high temperature by moulding in a vacuum bag in order to be able to obtain parts with complex geometry. The stack of PLLA films and flax mats was placed between two waxed steel plates in order to obtain smooth surfaces. The vacuum bag was placed over them and sealed with a joint, as for thermoset composites, and a vacuum was applied ( $\sim 0.95$ Bars). The manufacturing protocol is described elsewhere [20]. Fibre weight content was around $39 \%$. Biocomposite plate edges were protected from water penetration with a silicone mastic layer.

Neat PLLA plates $\left(200 \times 200 \mathrm{~mm}^{2}\right)$ were produced with a similar protocol.

\subsection{Experimental Methods}

2.3.1. Water Uptake. Ageing tests were performed in 60 litre capacity temperature controlled water baths. These were filled with natural seawater, pumped from the Brest Estuary (West France) and continuously renewed. As for previous studies [12] bath temperatures of 20 and $40^{\circ} \mathrm{C}$ were used. Temperatures above $20^{\circ} \mathrm{C}$ are used to accelerate the ageing mechanisms.

Biocomposite plates were immersed, removed periodically, the surfaces dried, weighed and replaced in the water baths. Weight gains were determined as a percentage of initial weight using the expression (1):

$$
W(\%)=\frac{W_{t}-W_{0}}{W_{0}} \times 100,
$$

where $W_{t}$ is the weight of the sample as a function of time $(t)$ and $W_{0}$ is the initial sample weight.

For each ageing temperature and duration 5 samples were dried until constant weight was reached under vacuum at room temperature (to avoid crystallization). This provides an indication of the reversibility of changes noted after ageing.

2.3.2. Thermal Analysis (DSC). Thermograms were obtained using a Mettler Toledo DSC. Calibration was performed with indium and tin in the temperature range $(+15$ to $+350^{\circ} \mathrm{C}$ ). Three samples of approximately $10 \mathrm{mg}$ of neat PLLA and biocomposite were analysed in order to get statistical results. The biocomposite coupons were taken at midthickness of the biocomposite for each condition in order to evaluate changes in the composite not the protective layers and were analysed in aluminium pans. All samples were first heated to $190^{\circ} \mathrm{C}$ for 3 minutes to remove thermal history in order to examine the irreversible degradation. All the peak temperatures measured $\left(T_{c}, T_{m}\right)$ have an accuracy of $\pm 0.5^{\circ} \mathrm{C}$. Nonisothermal crystallization and melting temperatures, $T_{c}$ and $T_{m}$, respectively, were determined from the crystallization peak extrema in experiments at heating/cooling rates of $\pm 20^{\circ} \mathrm{C} / \mathrm{min}$. Subsequent melting temperatures were obtained from the melting peaks maxima measured at a heating rate of $20^{\circ} \mathrm{C} / \mathrm{min}$. Melting enthalpies were determined using constant integration limits.

2.3.3. Mechanical Analysis. The tensile specimen is a dogbone geometry $100 \mathrm{~mm}$ long with central section dimensions of 7 by $2 \mathrm{~mm}^{2}$ (according to ISO 527). Quasistatic tensile tests were performed at a temperature of $23^{\circ} \mathrm{C}$ and $48 \%$ relative humidity. Samples were loaded at $1 \mathrm{~mm} / \mathrm{min}$. An extensometer with $25 \mathrm{~mm}$ gauge length was used to measure strain.

2.3.4. Scanning Election Microscopy (SEM). Fracture surfaces of samples aged for different periods were examined in a Jeol JSM 6460LV Scanning Electron Microscope. The samples were sputter-coated with a thin layer of gold in an Edwards Sputter Coater.

\section{Results and Interpretation}

3.1. Measurement of the PLLA Protective Layer Thickness. The use of vacuum bag moulding, in contrast to film stacking with heating plates [12], requires a layer of PLLA on the outer surfaces in order to avoid porosity. This is probably the result of the low applied pressure, as this type of reinforcement requires higher pressures [21]. The baseline reference material (Figure 1(a)) was developed after a series of trials in order to optimize the reduction of porosity and increase mechanical properties. As a result, it already has a thin PLLA surface layer, which is $192 \pm 26 \mu \mathrm{m}$ thick (Figure 1(a)). The variability of this thickness is caused by the heterogeneous nature of the flax fibre reinforcement, 25 measurements were made to determine this value. Thicker PLLA coatings were obtained by adding additional 


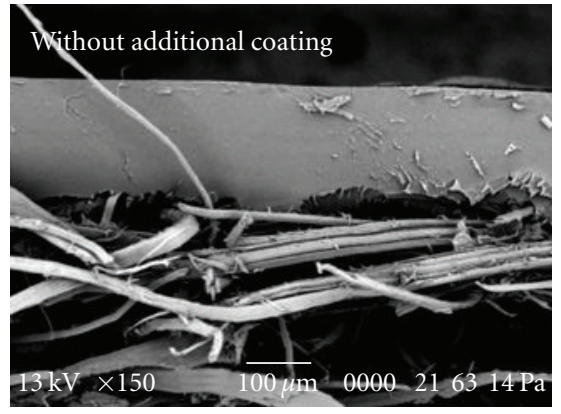

(a)

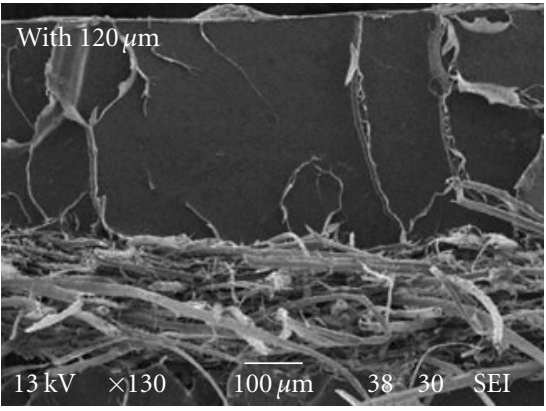

(b)

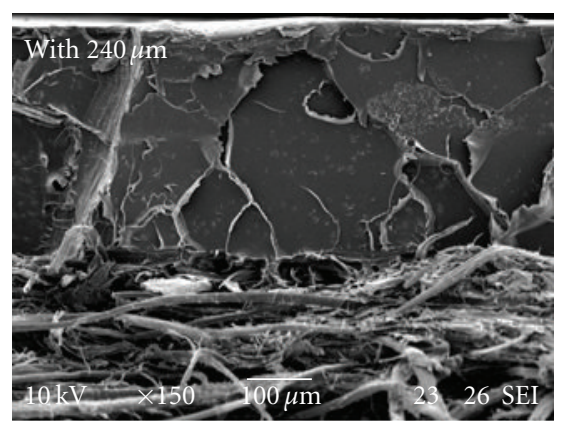

(c)

FIGURE 1: Fracture surface of biocomposites allowing thickness measurement. (a) Without additional coating; (b) With $120 \mu \mathrm{m}$; (c) With $240 \mu \mathrm{m}$.

layers, and two film thicknesses were added, 120 and $240 \mu \mathrm{m}$ (Figures 1(b) and 1(c)).

Adding $120 \mu \mathrm{m}$ of PLLA resulted in a total thickness of $350 \pm 7 \mu \mathrm{m}$ (Figure 1(b)), while with $240 \mu \mathrm{m}$, a total protection layer of $452 \pm 50 \mu \mathrm{m}$ was obtained (Figure 1(c)). These thicknesses are comparable to those of the gel coats used on boat hulls (a few tenths of a millimeter [22]).

3.2. Evolution of Weight during Ageing. Figure 2 shows how the addition of PLLA protective layers affects the weight gain of biocomposites during immersion at $40^{\circ} \mathrm{C}$. The PLLA alone is rapidly saturated, at a weight gain of around $1 \%$, as noted elsewhere [23].

Under the same immersion conditions the weight gain of the biocomposites protected by $192 \mu \mathrm{m}$ of PLLA is higher by a factor of 10 , due to the flax fibres hydrophilicity [24, 25]. However, a saturation plateau is not reached even after 3 months in water, in contrast to previous results [12]. This difference is caused by the manufacturing process; film stacking in a press and machined specimen edges were used previously which allowed the external PLLA layer thickness to be reduced and fibres to be directly in contact with water.

As shown in a previous study by Davies and Choqueuse [22] on carbon/epoxy composites, the PLLA layers are not a barrier to water but slow down the diffusion process, reducing the maximum weight gain by a factor of 2 . However, the difference between the two coating thicknesses of 350 and $452 \mu \mathrm{m}$ is small. This may be due to damage development and will be examined in Section 3.4.

\subsection{Evolution of Thermal and Mechanical Properties during Ageing}

3.3.1. Neat Polymer: PLLA. Figures 3(a) and 3(b) show how the glass transition temperature and melting enthalpy of PLLA changes during immersion at $20^{\circ} \mathrm{C}$ and $40^{\circ} \mathrm{C}$. $T_{g}$ is hardly affected by immersion $\left(20\right.$ and $\left.40^{\circ} \mathrm{C}\right)$ whereas the melting enthalpy tends to increase especially at $40^{\circ} \mathrm{C}$ $(+300 \%)$.

This phenomenon can be attributed to recrystallization, which involves a modification of the crystalline structure

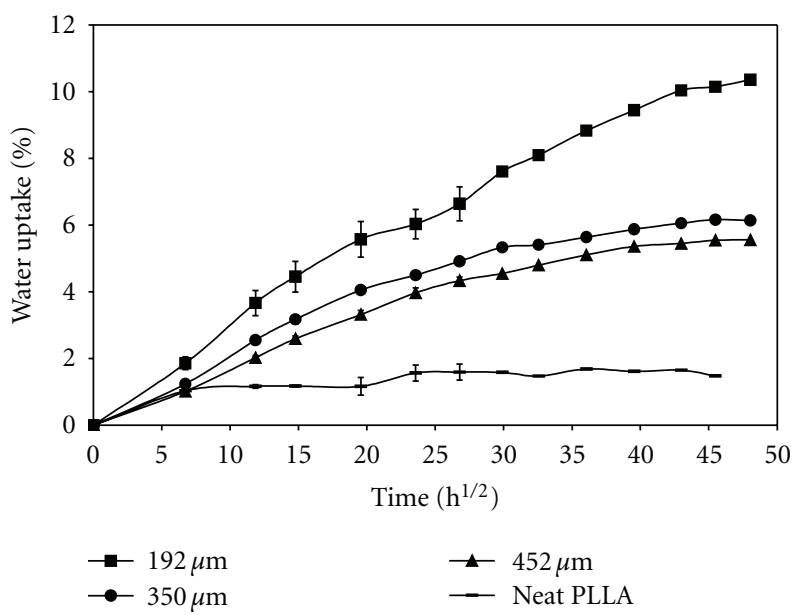

Figure 2: Effect of different PLLA protective layer thickness on biocomposite water uptake at $40^{\circ} \mathrm{C}$.

of the polymer. It has been reported previously for PET [26]. According to Foulc et al. [26] recrystallization is related to irreversible degradation mechanisms such as chain breakage due to hydrolysis of ester functions. Thus, smaller chains become more mobile, and the crystalline structure is modified. Previous work on PLLA [12] has highlighted a reduction by $48 \%$ of molar mass during seawater immersion at $40^{\circ} \mathrm{C}$, confirming chain breakage.

Table 1 shows the mechanical property data for the matrix polymer after 3 months in sea water at $20^{\circ} \mathrm{C}$ and $40^{\circ} \mathrm{C}$.

These results indicate an increase in Young's modulus of between $7 \%$ and $29 \%$ according to the temperature. The break stress drops by $15 \%$ and $48 \%$ after immersion at $20^{\circ} \mathrm{C}$ and $40^{\circ} \mathrm{C}$, respectively. Failure strain is unchanged by immersion at $20^{\circ} \mathrm{C}$ but drops by half at $40^{\circ} \mathrm{C}$. These trends can be explained by the hydrolysis phenomenon which affects the structural properties of PLLA. Concerning the Young's modulus evolution, the increase of melting enthalpy during immersion can compensate the consequences of chain breakage (Figure 3(b)). 


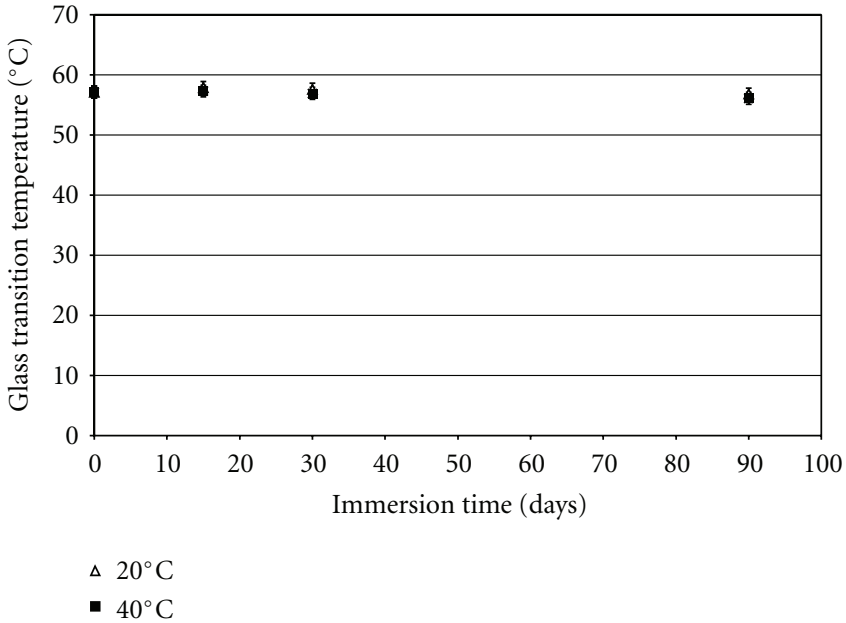

(a)

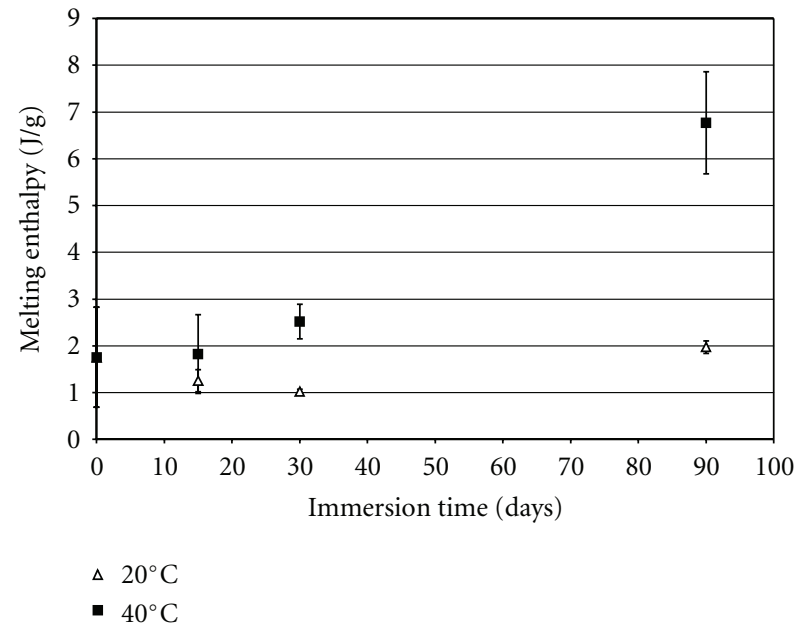

(b)

Figure 3: (a) Evolution of glass transition temperature. (b) Evolution of melting enthalpy versus immersion time for temperature bath of 20 and $40^{\circ} \mathrm{C}$.

TABle 1: Evolution of mechanical properties od neat PLLA after 3 months in seawater.

\begin{tabular}{lccc}
\hline Ageing temperature & Property at $t=0$ & Property at $t=3$ months & Evolution of properties (\%) \\
\hline $20^{\circ} \mathrm{C}$ & Young's modulus (MPa) & +7 \\
$40^{\circ} \mathrm{C}$ & $3823 \pm 23$ & $4102 \pm 143$ & +29 \\
\hline & & $4956 \pm 448$ & -15 \\
\hline $20^{\circ} \mathrm{C}$ & $49.6 \pm 3.9$ & $42.2 \pm 0.9$ & -48 \\
$40^{\circ} \mathrm{C}$ & & $26.2 \pm 2.7$ & \\
\hline & & Maximal Stress (MPa) & \\
\hline $20^{\circ} \mathrm{C}$ & $1.4 \pm 0.1$ & $1.4 \pm 0.1$ & -50 \\
$40^{\circ} \mathrm{C}$ & & $0.7 \pm 0.2$ & \\
\hline
\end{tabular}

Comparing these results with those from a previous study on PLLA from another supplier (Biomer L9000) [12], reveals faster degradation here, resulting probably from a lower initial molar mass $\left(M_{n}=63000\right.$ compared to $101000 \mathrm{~g} / \mathrm{mol}$ previously).

Seawater immersion induces complex mechanisms. Indeed, DSC results (Figures 3(a) and 3(b)) have shown irreversible degradation, while tests on PLLA after drying (not shown here) indicated complete recovery of initial properties up to 15 days immersion at both temperatures. Hence, both reversible ageing due to plasticization, appearing after short immersion times and permanent degradation (hydrolysis) occur during immersion.

3.3.2. Flax/PLLA Biocomposites. Analysis by DSC (Figures $4(\mathrm{a})$ and $4(\mathrm{~b}))$ reveals how the structure of the PLLA matrix in the biocomposite changes with immersion time.

The results show a small decrease of glass transition temperature with $192 \mu \mathrm{m}$ covered layer (Figure 4(a)) and a large increase in melting enthalpy of the composites with $192 \mu \mathrm{m}$ thick PLLA compared to those protected by 350 and $452 \mu \mathrm{m}$ layers. As explained in Section 3.3.1, the decrease of $T_{g}$ and increase of melting enthalpy can be explained by irreversible degradation of the matrix. The trend observed underlines the ability of the PLLA coating to slow down the degradation by hydrolysis due to reduction of water uptake (Figure 1). Once again results for 350 and $452 \mu \mathrm{m}$ PLLA are similar.

Figure 5 shows the evolution of the mechanical properties, apparent stiffness and load bearing capacity, of the biocomposites after immersion. These properties are simply calculated using the reference sample thickness, so the influence of the coating layers is neglected.

There is a clear drop in apparent stiffness, of between $40 \%$ and $60 \%$ according to the material (Figure 5) during the first month of immersion. Thereafter, the decrease in stiffness is less pronounced, particularly for the thicker coatings. The load bearing capacity (force flux) trend is similar.

Loss of mechanical properties can be due to chemical degradation of the PLLA matrix as evidenced by DSC measurement. Due to multicomponent system, degradation of reinforcement and interfacial area may have also occurred. Further details on the degradation mechanism are evaluated in Sections 3.4 and 3.5. 

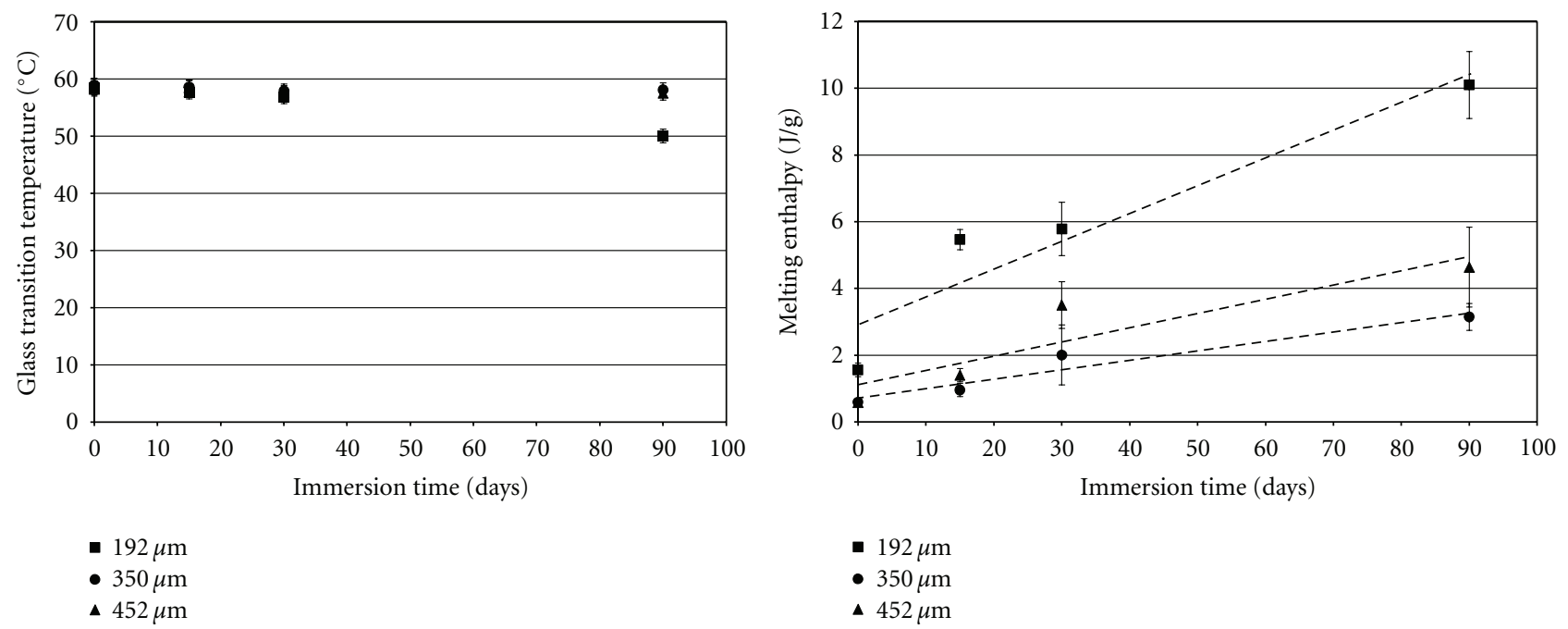

- $192 \mu \mathrm{m}$

- $350 \mu \mathrm{m}$

\ $452 \mu \mathrm{m}$

(a)

(b)

Figure 4: (a) Evolution of biocomposites glass transition temperature according to their protection layer thickness. (b) Evolution of biocomposites melting enthalpy Immersion temperature is $40^{\circ} \mathrm{C}$.

The protective layers clearly limit the drop in properties. Thus, after 3 months the specimens with 350 and $452 \mu \mathrm{m}$ thick PLLA coatings retain half their initial stiffness and $40 \%$ to $50 \%$ of their load-bearing capability. The difference between the results for 350 and $452 \mu \mathrm{m}$ thicknesses is small, as expected from the weight gain measurements.

3.4. Damage Mechanisms. Figure 6 shows how the mechanical response of biocomposites with different coatings tested in tension vary with ageing in sea water at $40^{\circ} \mathrm{C}$. One has to keep in mind that in composite with random in-plane oriented reinforcement, the loss of linearity corresponds to damage in the area where the reinforcement is oriented transversally to the loading direction. Interfacial properties between flax and PLLA influence the loss of linearity onset.

The changes in mechanical behaviour with immersion noted here confirm those measured in a previous study [12] with a loss of linearity of the stress-strain plot. This is the result of permanent damage such as fibre-matrix debonding and delamination due to differential swelling between flax and PLLA [12]. Degradation of flax fibres has been shown [12].

Figure 6 clearly shows the advantage of adding a PLLA coating to delay mechanical degradation. However, this coating does modify the damage mechanisms with first damage appearing at the surface (Figure 7). This has already been observed on common gel coat [27]. Thus, after 15 days' immersion cracks are noted at the surface, causing a sawtooth form to appear on the force-strain plots (highlighted by ellipses on Figure 6). This is a consequence of the drop in PLLA properties $(\varepsilon=0.7 \pm 0.2 \%$ after 3 months, Table 1$)$. With a thicker coating the first damage is detected earlier, suggesting that there is a practical upper limit to the thickness of PLLA which can be added. The surface crack density is much higher for the thinner coating. The appearance of these cracks will lead to an acceleration in weight gain and explains the drop in mechanical properties.

Then SEM images (Figure 8) illustrating damage in the biocomposites after 3 months in seawater at $40^{\circ} \mathrm{C}$ show that the specimens with $192 \mu \mathrm{m}$ PLLA damage globally (cracks in the PLLA matrix, debonding, fibre break, etc.). For thicker coatings ( 350 and $452 \mu \mathrm{m}$ ), damage is more local with delamination between the biocomposite and the PPLA surface layer (red rectangle in Figure 8). Differential swelling between the biocomposite and the coating layers may cause this delamination.

3.5. Influence of Drying and Correlation with Water Uptake. Some specimens were dried until constant weight was reached before testing in order to distinguish between reversible and permanent ageing damage. Figure 9 shows how the mechanical properties of the biocomposites vary after ageing ((a) apparent stiffness and (b) force flux).

The results on Figures 9(a) and 9(b) show that drying enables stiffness properties to be recovered, at least up to $4 \%$ weight gain but not strength. This highlights that reversible (plasticization) and irreversible phenomenon (hydrolysis, debonding, etc.) are occurring simultaneously.

It is also interesting to note the influence of coating. Indeed, drying of coated biocomposites does not result in as much stiffness recovery as uncoated materials for a given weight gain. This is probably due to the additional damage in the zone between the coating and the composite (Figure 7).

Finally, the results in Figures 9(a) and 9(b) show that the relationship between mechanical properties and weight gain is close to linear. This underlines the importance of restricting water entry by suitable coating strategies. It also suggests that predictions of the durability of these materials can be made quite simply, by coupling a diffusion model to obtain the water profile in the material with a linear property 


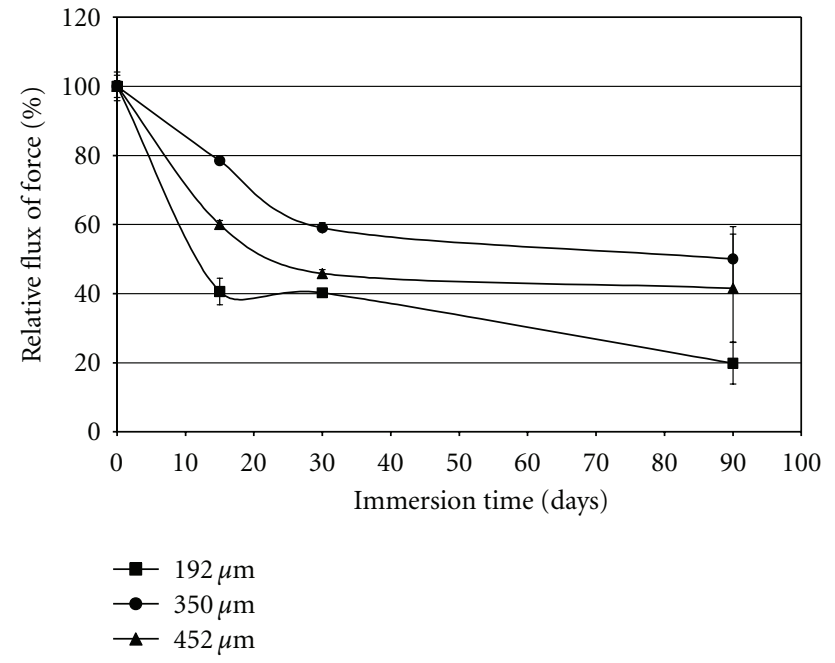

(a)

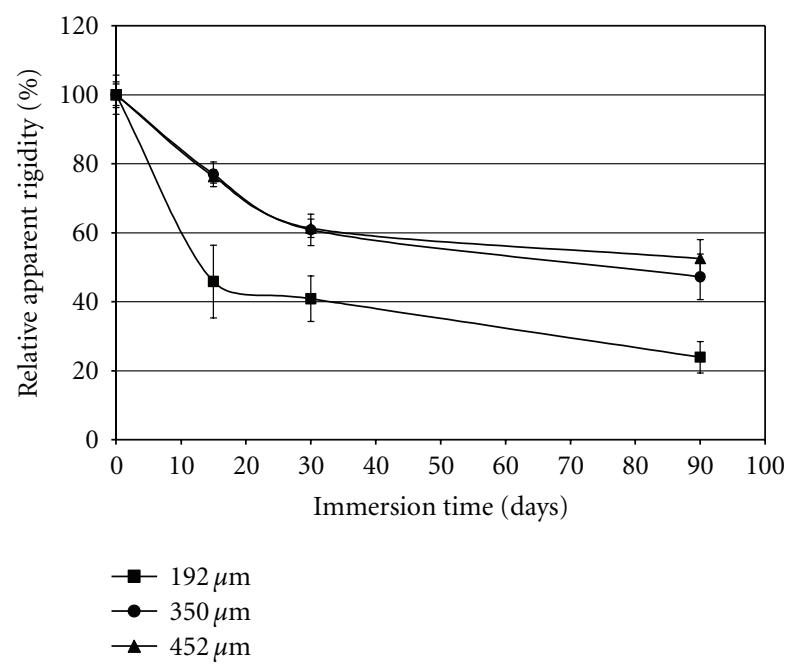

(b)

FIGURE 5: Retention of (a) apparent rigidity and (b) relative force flux, as a function of immersion time at $40^{\circ} \mathrm{C}$.

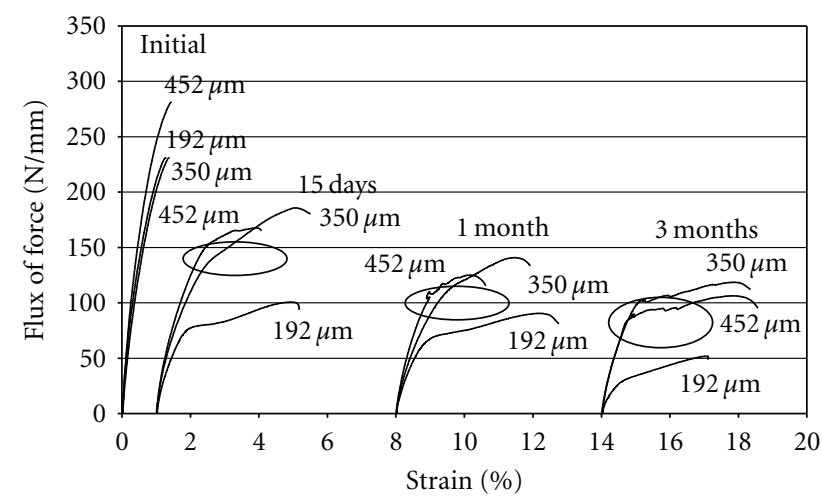

FIgURE 6: Evolution of tensile mechanical behaviour of biocomposites according to their protective layer thickness as a function of immersion time. Immersion temperature is $40^{\circ} \mathrm{C}$.

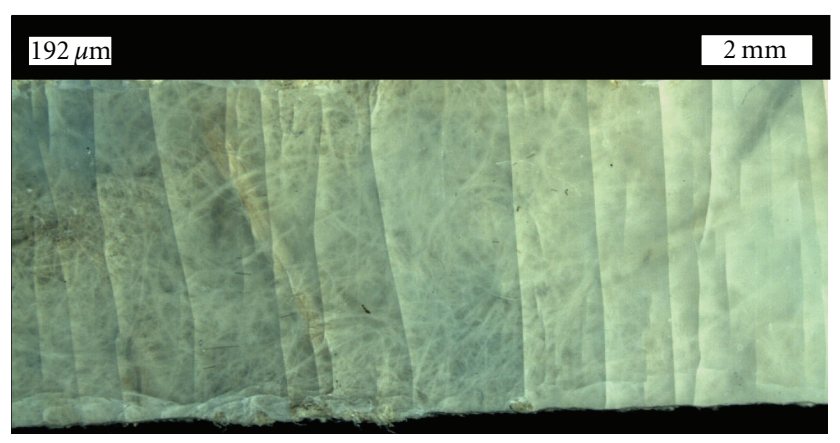

(a)

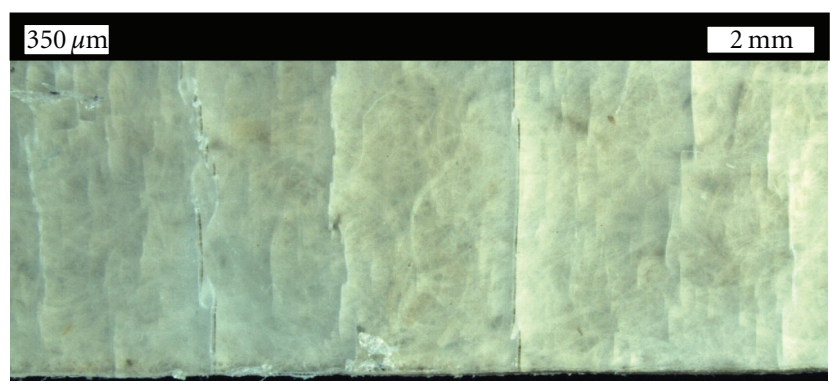

(b)

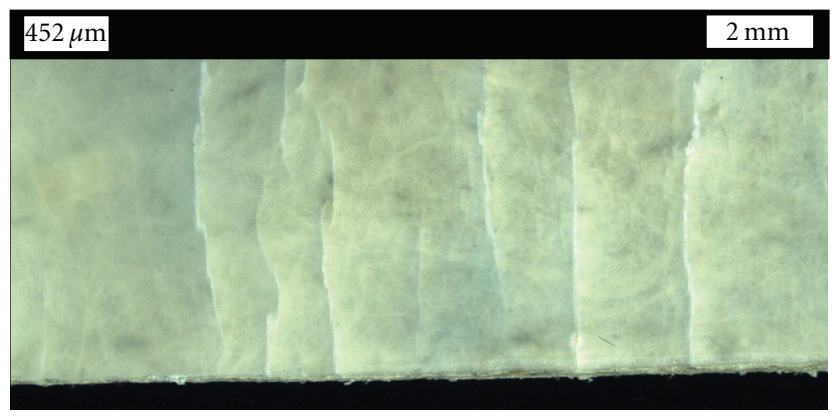

(c)

Figure 7: Damage mechanism of aged samples after 3 months at $40^{\circ} \mathrm{C}$. Arrows show damage on the protective layer.

loss-water dependency. Similar coupled models have been applied for ageing of other materials [28].

\section{Conclusion}

In a previous study [12], large weight gains after ageing were shown to result in a large drop in flax/PLLA biocomposite mechanical properties. In parallel, the properties of PLLA were shown to remain quite stable after ageing. The aim of the present work was to evaluate the benefits after ageing of the addition of extra PLLA layers to the surface of a flax/PLLA biocomposite, in a similar way to the gel coats used to protect traditional glass reinforced composites from marine ageing. A major advantage of this approach is that the coating can be added during moulding so that extra operations are not necessary, and the end-of life management remains unchanged. 


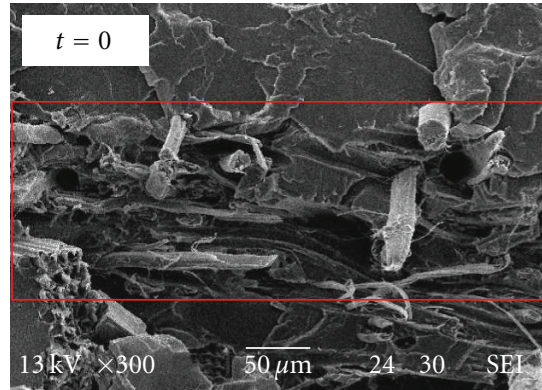

(a)

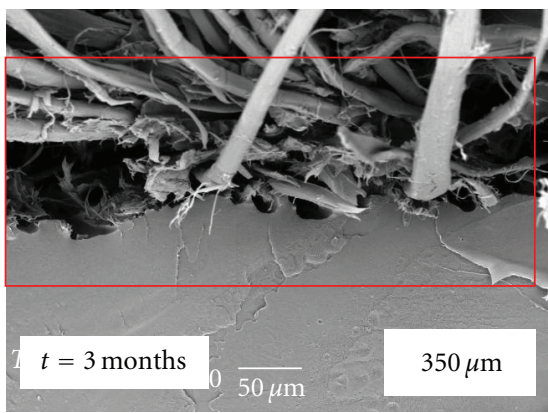

(c)

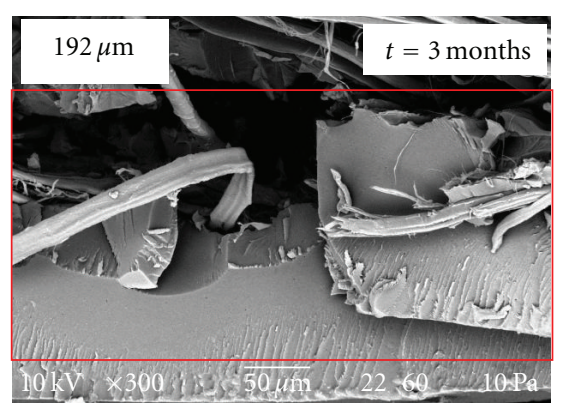

(b)

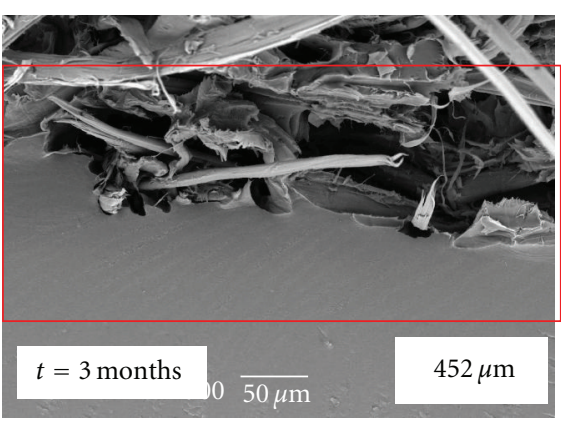

(d)

FIGURE 8: Influence of the protective layer thickness on the damage mechanism of biocomposites after 3 months of immersion at $40^{\circ} \mathrm{C}$.

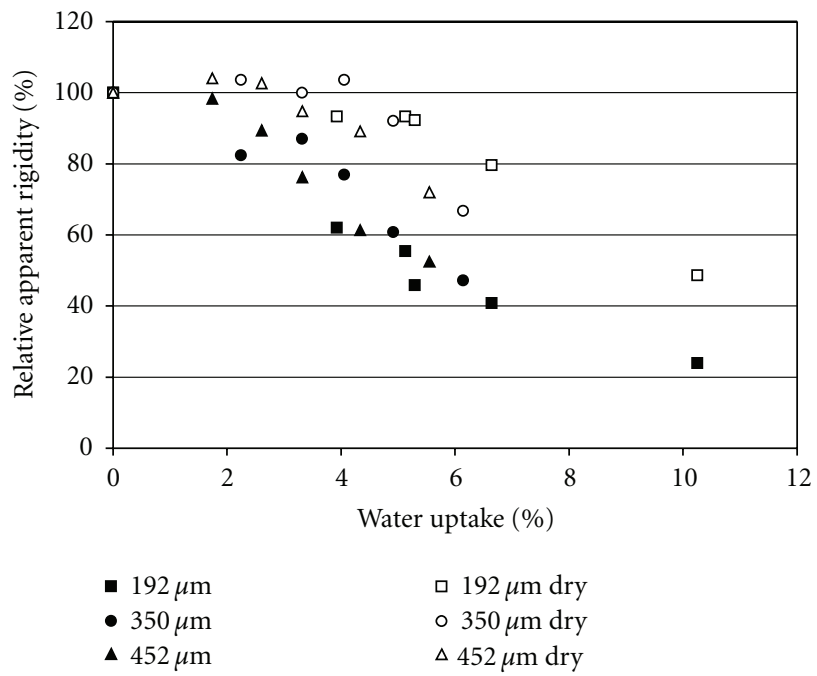

(a)

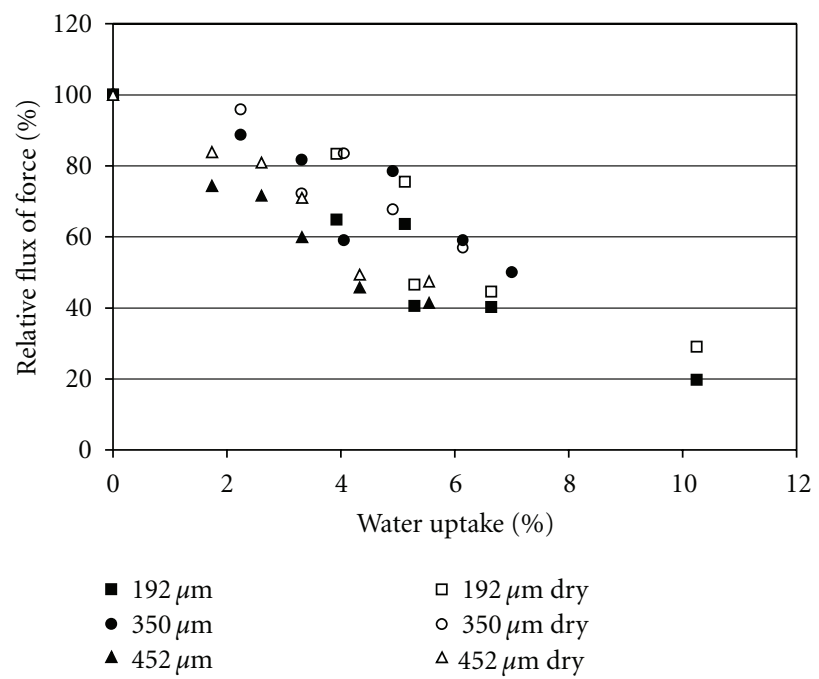

(b)

FIGURE 9: Evolution of relative rigidity (a) and relative flux of force (b) as a function of water uptake for wet samples (full symbol) and for dried samples (empty symbols).

Weight gain measurements show that the addition of PLLA (350 and $452 \mu \mathrm{m}$ thick) slows the weight gain by a factor of 2. The analysis of thermal and mechanical properties of the biocomposite after immersion shows that the protective layers reduce hydrolysis of the matrix and the retained composite properties are improved by $100 \%$ compared to those of the unprotected reference material.
This is a first approach to improving the durability of biocomposites for marine applications while retaining an environmentally friendly strategy. Addition of a thick PLLA coating results in a new damage mechanism, surface layer cracking, and this highlights the need for a more ductile (and UV resistant) coating layer. Further work is underway in this direction. 


\section{References}

[1] E. Bodros, I. Pillin, N. Montrelay, and C. Baley, "Could biopolymers reinforced by randomly scattered flax fibre be used in structural applications?" Composites Science and Technology, vol. 67, no. 3-4, pp. 462-470, 2007.

[2] A. Le Duigou, P. Davies, and C. Baley, "Macroscopic analysis of interfacial properties of flax/PLLA biocomposites," Composites Science and Technology, vol. 70, no. 11, pp. 1612-1620, 2010.

[3] A. Le Duigou, P. Davies, and C. Baley, "Analyse du cycle de vie d'un biocomposite," Matériaux et Techniques, vol. 98, no. 2, pp. 143-150, 2010.

[4] A. Le Duigou, P. Davies, and C. Baley, "Environmental impact analysis of the production of flax fibres to be used as composite material reinforcement," Journal of Biobased Materials and Bioenergy, vol. 5, no. 1, pp. 153-165, 2011.

[5] A. Le Duigou, I. Pillin, A. Bourmaud, P. Davies, and C. Baley, "Effect of recycling on mechanical behaviour of biocompostable flax/poly(l-lactide) composites," Composites Part A, vol. 39, no. 9, pp. 1471-1478, 2008.

[6] R. Kumar, M. K. Yakubu, and R. D. Anandjiwala, "Biodegradation of flax fiber reinforced poly lactic acid," Express Polymer Letters, vol. 4, no. 7, pp. 423-430, 2010.

[7] A. Bourmaud and C. Baley, "Effects of thermo mechanical processing on the mechanical properties of biocomposite flax fibers evaluated by nanoindentation," Polymer Degradation and Stability, vol. 95, no. 9, pp. 1488-1494, 2010.

[8] C. Baley, C. Morvan, and Y. Grohens, "Influence of the absorbed water on the tensile strength of flax fibers," in PolymerSolvent Complexes and Intercalates V, Y. Grohens, Ed., Wiley, Lorient, UK, 2007.

[9] M. C. Symington, W. M. Banks, O. D. West, and R. A. Pethrick, "Tensile testing of cellulose based natural fibers for structural composite applications," Journal of Composite Materials, vol. 43, no. 9, pp. 1083-1108, 2009.

[10] K. Charlet, C. Baley, C. Morvan, J. P. Jernot, M. Gomina, and J. Bréard, "Characteristics of Hermès flax fibres as a function of their location in the stem and properties of the derived unidirectional composites," Composites Part A, vol. 38, no. 8, pp. 1912-1921, 2007.

[11] C. Baley, "Analysis of the flax fibres tensile behaviour and analysis of the tensile stiffness increase," Composites Part A, vol. 33, no. 7, pp. 939-948, 2002.

[12] A. Le Duigou, P. Davies, and C. Baley, "Seawater ageing of flax/poly(lactic acid) biocomposites," Polymer Degradation and Stability, vol. 94, no. 7, pp. 1151-1162, 2009.

[13] R. H. Hu, M. Y. Sun, and J. K. Lim, "Moisture absorption, tensile strength and microstructure evolution of short jute fiber/polylactide composite in hygrothermal environment," Materials and Design, vol. 31, no. 7, pp. 3167-3173, 2010.

[14] M. S. Islam, K. L. Pickering, and N. J. Foreman, "Influence of accelerated ageing on the physico-mechanical properties of alkali-treated industrial hemp fibre reinforced poly(lactic acid) (PLA) composites," Polymer Degradation and Stability, vol. 95, no. 1, pp. 59-65, 2010.

[15] A. Arbelaiz, B. Fernández, J. A. Ramos, A. Retegi, R. LlanoPonte, and I. Mondragon, "Mechanical properties of short flax fibre bundle/polypropylene composites: influence of matrix/fibre modification, fibre content, water uptake and recycling," Composites Science and Technology, vol. 65, no. 10, pp. 1582-1592, 2005.

[16] P. A. Sreekumar, S. P. Thomas, J. M. Saiter, K. Joseph, G. Unnikrishnan, and S. Thomas, "Effect of fiber surface mod- ification on the mechanical and water absorption characteristics of sisal/polyester composites fabricated by resin transfer molding," Composites Part A, vol. 40, no. 11, pp. 1777-1784, 2009.

[17] A. Bessadok, S. Marais, F. Gouanvé et al., "Effect of chemical treatments of alfa (Stipa tenacissima) fibres on water-sorption properties," Composites Science and Technology, vol. 67, no. 34, pp. 685-697, 2007.

[18] H. Tsuji and K. Suzuyoshi, "Environmental degradation of biodegradable polyesters 1 . Poly(caprolactone), poly[(R)-3hydroxybutyrate], and poly(L-lactide) films in controlled static seawater," Polymer Degradation and Stability, vol. 75, no. 2, pp. 347-355, 2002.

[19] C. Baley and E. Bodros, "Biocomposite à matrice PLLA renforcés par des mats de lin," Revue des Composites et des Matériaux Avancés, vol. 16, no. 1, pp. 129-139, 2006.

[20] A. Le Duigou, J.-M. Deux, P. Davies, and C. Baley, "PLLA/Flax Mat/Balsa bio-sandwich manufacture and mechanical properties," Applied Composite Materials. In press.

[21] P. Ouagne, L. Bizet, C. Baley, and J. Bréard, "Analysis of the film-stacking processing parameters for PLLA/Flax fiber biocomposites," Journal of Composite Materials, vol. 44, no. 10, pp. 1201-1215, 2010.

[22] P. Davies and D. Choqueuse, "Ageing of composites in underwater applications," in Ageing of Composites, R. Martin, Ed., Woodhead Publishing, Cambridge, UK, 2009.

[23] G. H. Yew, A. M. Mohd Yusof, Z. A. Mohd Ishak, and U. S. Ishiaku, "Water absorption and enzymatic degradation of poly(lactic acid)/rice starch composites," Polymer Degradation and Stability, vol. 90, no. 3, pp. 488-500, 2005.

[24] S.-H. Lee and S. Wang, "Biodegradable polymers/bamboo fiber biocomposite with bio-based coupling agent," Composites Part A, vol. 37, no. 1, pp. 80-91, 2006.

[25] C. P. L. Chow, X. S. Xing, and R. K. Y. Li, "Moisture absorption studies of sisal fibre reinforced polypropylene composites," Composites Science and Technology, vol. 67, no. 2, pp. 306-313, 2007.

[26] M. P. Foulc, A. Bergeret, L. Ferry, P. Ienny, and A. Crespy, "Study of hygrothermal ageing of glass fibre reinforced PET composites," Polymer Degradation and Stability, vol. 89, no. 3, pp. 461-470, 2005.

[27] E. Greene, Marine Composites, Eric Greene Associates, Annapolis, Md, USA, 2nd edition, http://www.marinecomposites.com/.

[28] M. Bordes, P. Davies, J.-Y. Cognard, L. Sohier, V. SauvantMoynot, and J. Galy, "Prediction of long term strength of adhesively bonded steel/epoxy joints in sea water," International Journal of Adhesion and Adhesives, vol. 29, no. 6, pp. 595-608, 2009. 

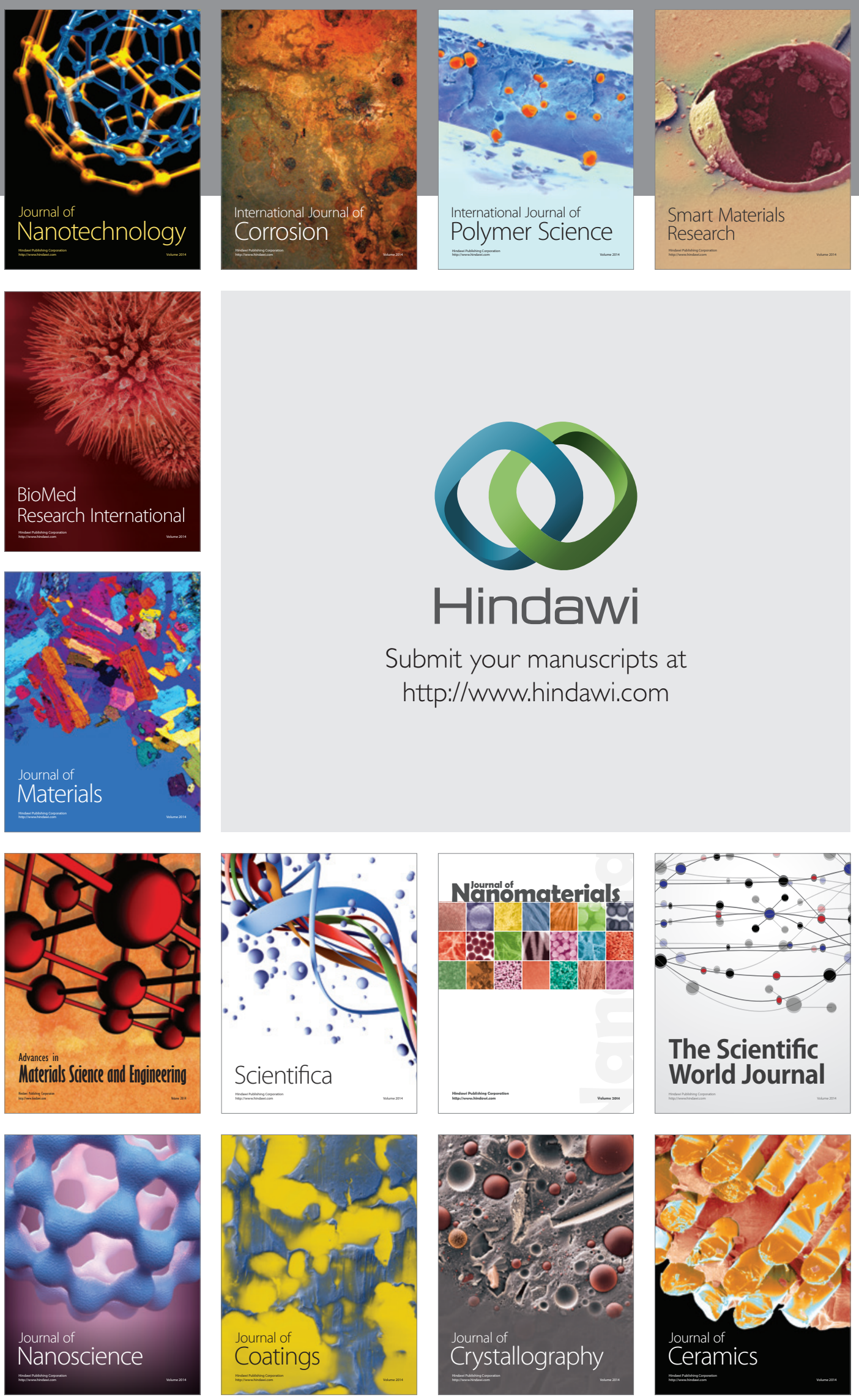

The Scientific World Journal

Submit your manuscripts at

http://www.hindawi.com

\section{World Journal}

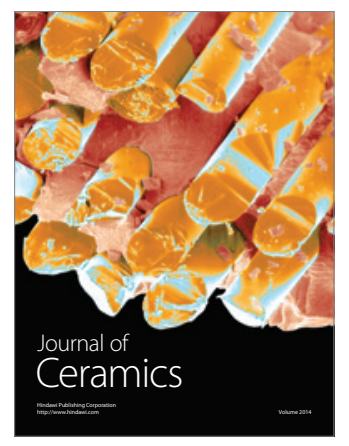

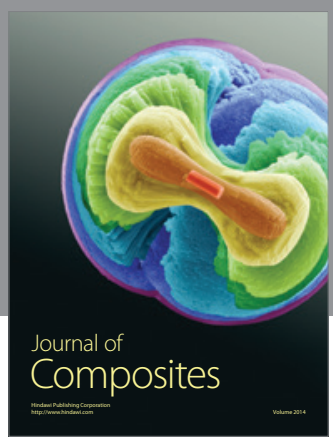
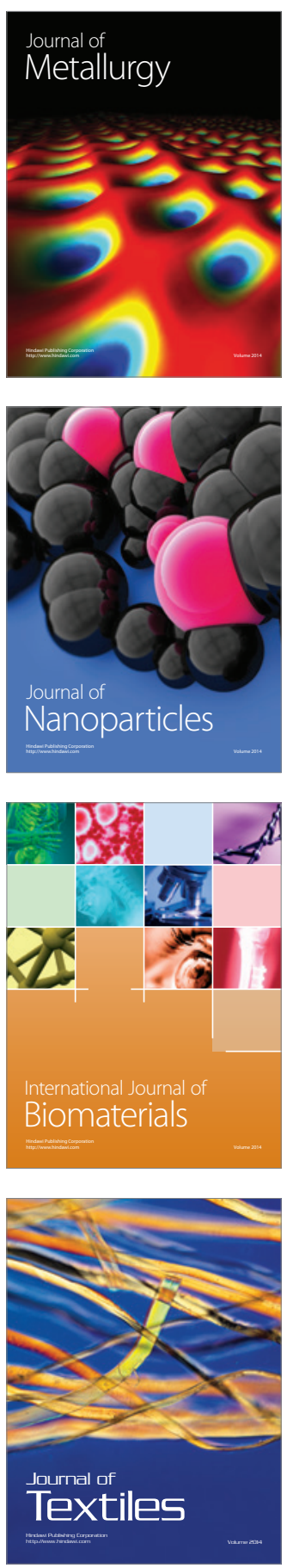